\title{
The role of fatal family history and mode of inheritance in prostate cancer for long-term outcomes following radical prostatectomy
}

\author{
Valentin H. Meissner ${ }^{1}$. Jamila G. H. Strüh ${ }^{1}$ - Martina Kron ${ }^{2}$ - Lea A. Liesenfeld ${ }^{1}$. Stephanie Kranz ${ }^{1}$. \\ Jürgen E. Gschwend ${ }^{1} \cdot$ Kathleen Herkommer ${ }^{1}$ (])
}

Received: 3 December 2019 / Accepted: 26 February 2020 / Published online: 11 March 2020

(c) The Author(s) 2020

\begin{abstract}
Purpose To determine whether fatal family history (FFH) or mode of inheritance in prostate cancer (PCa) has an impact on long-term outcomes following radical prostatectomy (RP).

Methods $1076 \mathrm{PCa}$ patients after RP with at least one deceased first-degree relative with PCa were included and stratified by FFH (four subgroups: fraternal, paternal, multiple, and none) and by mode of inheritance (two subgroups: male to male, non-male to male). We compared clinicopathological characteristics between subgroups with Fisher's exact or Chi-square tests. Biochemical recurrence-free survival (BRFS) and cancer-specific survival (CSS) were analyzed using the method of Kaplan and Meier. Simple and multiple Cox regression with backward elimination were performed to select prognostic factors for BRFS and CSS.

Results Median age at surgery was 63.3 (range 35.9-79.4) years. The overall Kaplan-Meier estimated BRFS rate at 10 and 15 years was $65.6 \%$ and $57.0 \%$, respectively. The overall Kaplan-Meier estimated CSS rate at 10 and 15 years was $98.1 \%$ and $95.7 \%$, respectively. Neither FFH nor mode of inheritance were factors associated with worse BRFS. However, in multiple Cox regression, paternal FFH was an important prognostic factor for a better CSS (HR 0.19, CI 0.05-0.71, $p=0.014$ ) compared to non-FFH.

Conclusion FFH and mode of inheritance do not seem to be prognostic factors of worse long-term outcomes following RP. Rather, a paternal FFH was associated with a better CSS; however, the reasons remain unclear. Nevertheless, patients after RP and FFH could be reassured that their own PCa diagnosis is not associated with a worse long-term outcome.
\end{abstract}

Keywords Biochemical recurrence-free survival · Cancer-specific survival · Fatal family history $\cdot$ Mode of inheritance · Prostatic neoplasms $\cdot$ Radical prostatectomy

$\begin{array}{ll}\text { Abbreviations } \\ \text { BRCA } 1,2 & \text { BReast CAncer } 1,2 \\ \text { BRFS } & \text { Biochemical recurrence-free survival } \\ \text { CSS } & \text { Cancer-specific survival } \\ \text { FFH } & \text { Fatal family history } \\ \text { FH } & \text { Family history } \\ \text { f/p/m/n } & \text { Fraternal/paternal/multiple/none } \\ \text { HOXB13 } & \text { Homeobox protein } 13 \\ \text { MTM } & \text { Male to male }\end{array}$

Kathleen Herkommer

kathleen.herkommer@tum.de

1 Technical University of Munich, School of Medicine, Klinikum rechts der Isar, Department of Urology, Munich, Germany

2 Institute of Epidemiology and Medical Biometrics, University of Ulm, Ulm, Germany

$\begin{array}{ll}\text { PCa } & \text { Prostate cancer } \\ \text { PSA } & \text { Prostate-specific antigen } \\ \text { RP } & \text { Radical prostatectomy }\end{array}$

\section{Introduction}

A positive family history $(\mathrm{FH})$ of prostate cancer $(\mathrm{PCa})$ is a well-known risk factor for PCa in addition to age and ethnicity [1-3]. Nevertheless, it remains difficult to inform PCa patients with a positive $\mathrm{FH}$ about the outcome of the disease. Although a positive FH has been found to be associated with earlier onset and lower grade tumors [4-6], there are conflicting results regarding long-term outcomes, i.e., biochemical recurrence-free survival (BRFS) and cancerspecific survival (CSS) [4, 7-11]. 
The strong genetic component of the disease additionally raises the question whether familial risks are higher for fatal than incident PCa. Investigating the impact of fatal family history (FFH) on the outcome after radical prostatectomy could provide a new approach towards better understanding the role of familial PCa and improve clinical counseling of affected patients. Indeed, previous studies from the Swedish cancer registry reported higher hazard ratios (HRs) of death from PCa in relatives of men who died from PCa [10, 11]. A recent American study reported on opposing outcome results: FFH was not associated with BRFS or clinicopathological characteristics compared to non-fatal or negative $\mathrm{FH}$ [12]. Since both studies had major limitations (lacked data on clinical characteristics and treatment [10] as well as insufficient sample sizes [10, 12] and follow-up periods [12]), it remains difficult to draw valid conclusions for patient counseling.

When investigating familial $\mathrm{PCa}$, mode of inheritance is another important aspect that needs to be considered, as genetic susceptibility is a possible explanation for familial aggregation. To date, there are three known gene mutations (BRCA 1, BRCA2, and HOXB13) [13, 14] and several singlenucleotide polymorphisms [15] associated with an increased risk for PCa. However, this factor often remains neglected in the literature, although there is a need for further evaluation.

The objective of the present study was to analyze whether FFH or mode of inheritance is prognostic factors for long-term outcomes following radical prostatectomy, i.e., BRFS and CSS, and whether there are differences among the analyzed subgroups regarding clinicopathological characteristics.

\section{Materials and methods}

\section{Database and study population}

Data were obtained from the multicenter German Familial Prostate Cancer database consisting of more than 36,000 index patients and their relatives. Since 1993, this prospective study consecutively recruits and surveys newly diagnosed patients with PCa independent of the FH through cooperating clinics and urologists throughout Germany. Each year, patients provide information about sociodemographic and clinical characteristics as well as FH via questionnaires. Self-reported FH of PCa is verified by a histopathological report or a doctor's letter. Verified, affected relatives are added to the database. Informed consent is obtained from each patient. More detailed descriptions of the database have been published previously $[7,16]$
For the present analysis, we retrospectively identified 1248 patients with a first-degree $\mathrm{FH}$ and with at least one deceased first-degree relative affected with PCa to ensure a definite classification. Furthermore, patients with primary therapies of $\mathrm{PCa}$ other than radical prostatectomy $(n=153)$ or with neoadjuvant therapy $(n=19)$ were excluded and 1076 were left for further analysis.

Defined by the cause of death of the deceased first-degree relative with $\mathrm{PCa}$, patients were subdivided into four $\mathrm{FFH}$ subgroups:

- (fraternal) fFFH: brother died of PCa

- (paternal) pFFH: father died of PCa

- (multiple) mFFH: at least two first-degree relatives died of $\mathrm{PCa}$

- (none) nFFH: deceased first-degree relative(s) died of something other than $\mathrm{PCa}$

Based on information on the patient's pedigree, patients were subdivided into two mode of inheritance subgroups:

- male to male (MTM): paternal mode of inheritance (father affected)

- non-male to male (nMTM): maternal mode of inheritance (only brothers affected)

\section{Statistical analysis}

All subgroups were compared with regard to the following clinicopathological characteristics using Chi-square tests or the Fisher's exact test in case of low counts: Heritability of PCa according to the Johns Hopkins criteria [(1) PCa in at least three first-degree relatives, or (2) PCa in three consecutive generations, or (3) PCa in two first-degree relatives with an age of onset $<55$ years] [17], age at surgery, PSA level at diagnosis, TNM classification, surgical margin, pathological Gleason score, adjuvant radiotherapy, and adjuvant hormone therapy. Pathological staging was classified or reclassified for patients diagnosed before 2002 using the UICC TNM classification 2002 for prostatectomy specimens.

Kaplan-Meier analysis was performed to determine the overall BRFS and CSS rates. Analyses were run overall and stratified by FFH and mode of inheritance. Survival rates at 5 , 10 , and 15 years were calculated with $95 \%$ confidence intervals (CI). Any of the potential prognostic factors (Table 1) for BRFS and CSS were examined using simple Cox regression. Multiple Cox regression with backward elimination (selection level 5\%) was carried out to simultaneously assess potential prognostic factors. Hazard ratios (HR) with $95 \%$ confidence intervals and $p$ values were calculated. 


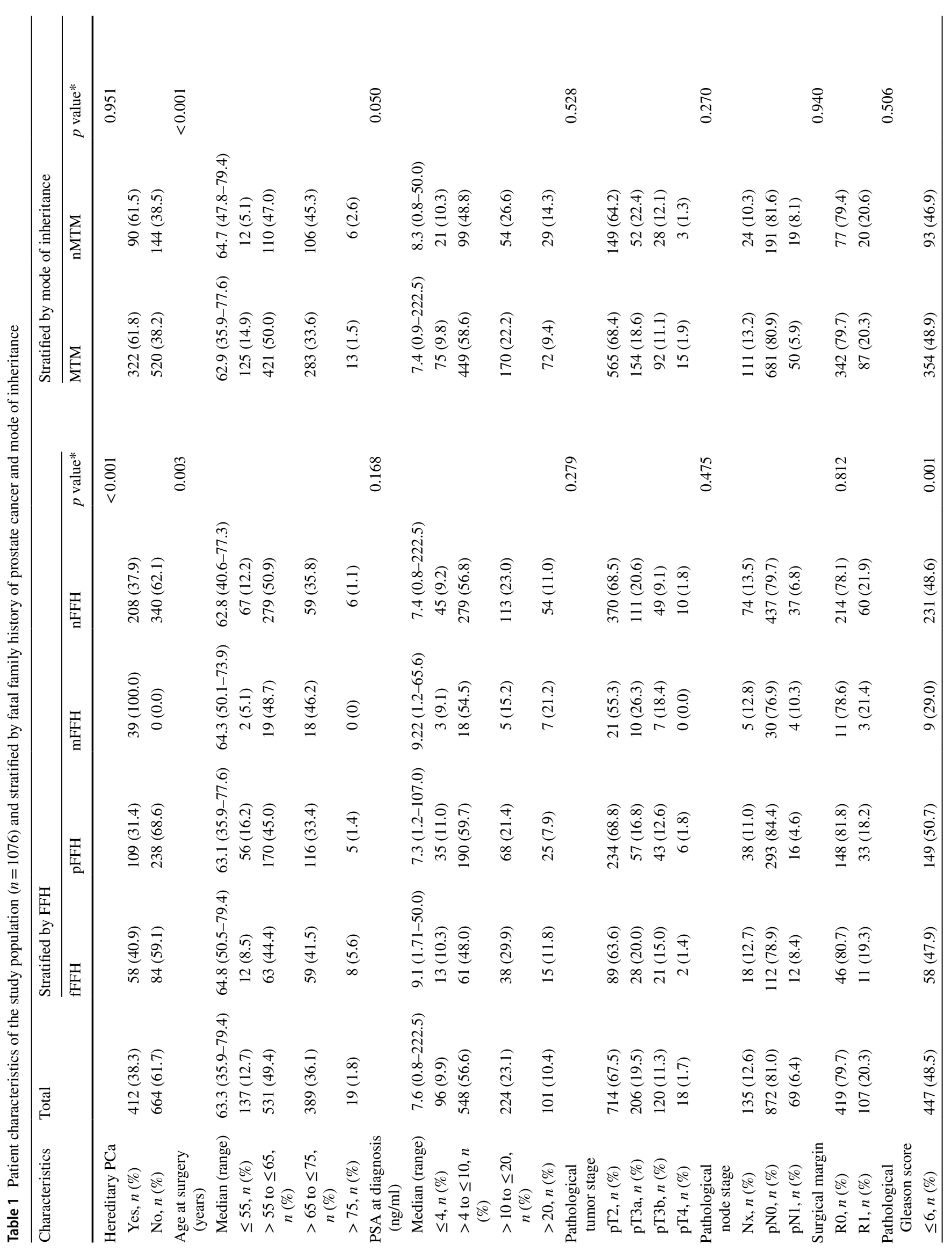




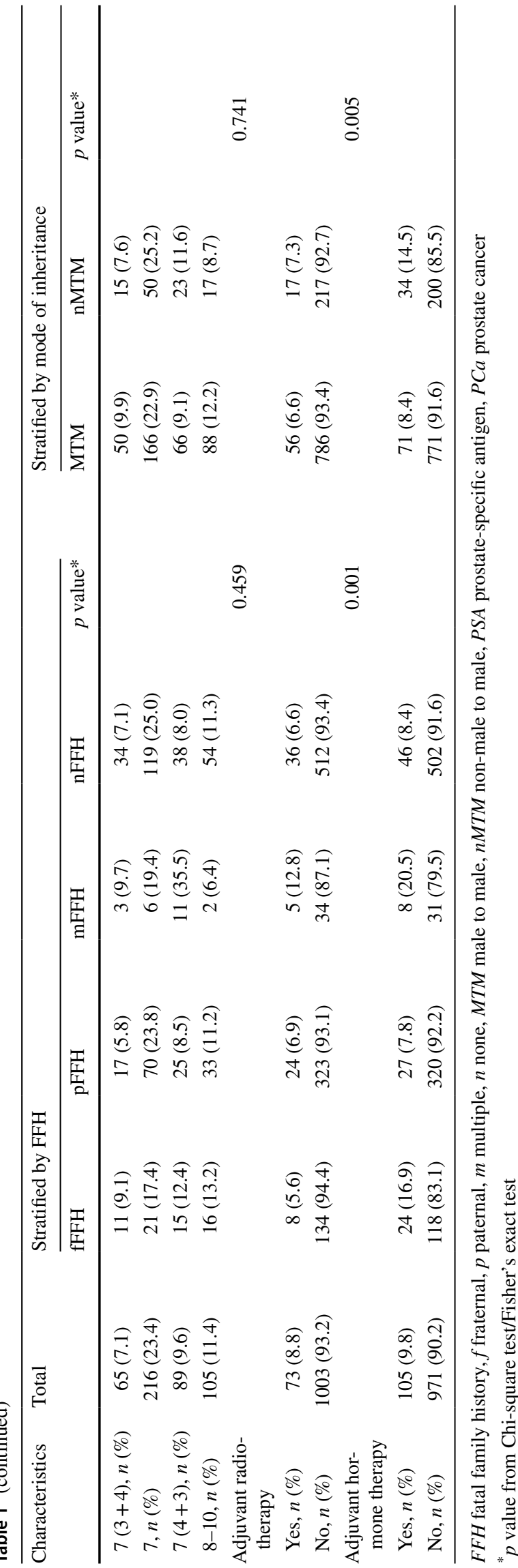

\section{Results}

\section{Patient characteristics}

1076 patients were included in the final analysis. Median age at surgery was 63.3 (range 35.9-79.4) years and median PSA at diagnosis was 7.6 (range 0.8-222.5) $\mathrm{ng} / \mathrm{ml}$. The median follow-up was 9.7 (range $0.3-26.3$ ) years. More than a third of the patients (38.3\%) met the Johns Hopkins criteria for hereditary PCa. Regarding mode of inheritance, $78.3 \%$ of the patients were categorized into the MTM group, and $21.7 \%$ into the nMTM group. Regarding FFH of PCa, $13.2 \%$ of the patients were categorized into the fFFH group, $32.2 \%$ into the pFFH group, $3.6 \%$ into the mFFH group, and $50.9 \%$ into the nFFH group (Table 1). The overall BRFS after 5, 10, and 15 years was $78.9 \%, 65.6 \%$, and $57.0 \%$, respectively. The overall 5-, 10-, and 15-year CSS was $99.3 \%, 98.1 \%$, and $95.7 \%$, respectively.

\section{Fatal family history}

Men with an $\mathrm{nFFH}$ and a pFFH subgroups were younger at surgery (median: 62.8 and 63.1 years) compared to men with an fFFH and an mFFH (median: 64.8 and 64.3 years) $(p<0.001)$. Men with a pFFH were more often diagnosed with a lower pathological Gleason score $(p=0.001)$ and treated less often with adjuvant hormone therapy $(p=0.001)$ compared to the other subgroups (Table 1).

Neither Kaplan-Meier estimated BRFS rates (Fig. 1a) nor CSS rates (Fig. 1b) differed among the four FFH subgroups.

In simple Cox regression, neither BRFS nor CSS were associated with FFH (Table 2). In multiple Cox regression, however, an important prognostic factor for CSS was FFH showing the lowest risk for pFFH (HR 0.19, CI 0.05-0.71) (Table 2).

\section{Mode of inheritance}

Men with a paternal mode of inheritance (MTM group) were younger at surgery (median: 62.9 vs. 64.7 years; $p<0.001$ ) and had a lower PSA value at diagnosis (median: 7.4 vs. $8.3 \mathrm{ng} / \mathrm{ml} ; p=0.050)$ compared to men with a maternal mode of inheritance (nMTM group) (Table 1).

The Kaplan-Meier estimated BRFS rate did not differ among the MTM and nMTM groups (Fig. 2a); however, the Kaplan-Meier estimated CSS rate was higher in the MTM group (Fig. 2b).

In the simple Cox regression, mode of inheritance was not associated with BRFS $(p=0.736)$, but nMTM mode of inheritance was associated with a worse CSS (HR 2.5, CI 
1.24-5.04, $p=0.010$ ) (Table 2). On multiple Cox regression, however, mode of inheritance was not selected (Table 2).

\section{Discussion}

Aggressive PCa in a first-degree relative as well as an FFH of PCa might lead to anxiety in PCa patients. Thus, there is a need for profound medical counseling regarding long-term outcomes in these patients. As previous studies reported conflicting results whether an FFH of PCa increases the patient's risk of dying due to $\mathrm{PCa}$, the objective of this study was to analyze this factor in-depth in a large patient sample following radical prostatectomy [10, 12].

Our results are based on a large, representative German sample of 1,076 $\mathrm{PCa}$ patients after radical prostatectomy with a verified FH of PCa. The 5-year BRFS (78.9\%) and CSS (99.3\%) rates are comparable to those of another large, German collective of PCa patients after radical prostatectomy from a high-volume center (5-year BRFS: 76.9\%; 5-year CSS: $99.0 \%$ ) which confirms the representativeness [18].

In 2010, a study based on the Swedish cancer registry assessed for the first time whether the risk of dying from $\mathrm{PCa}$ is higher in men with an FFH. Brandt et al. reported higher HRs of death from PCa for men with a father or brother who died from PCa (HR 2.08, HR 2.30) compared to men with a negative $\mathrm{FH}$ of PCa. The highest HR was found when both father and brother died from PCa (HR: 6.86). However, HRs were assessed compared to men with a negative $\mathrm{FH}$ of $\mathrm{PCa}$ and not to an $\mathrm{nFFH}$ and the sample size was very low (pFFH: $n=202$; fFFH: $n=15$; men with a deceased father and brother $n=4$ ) [10]. Hemminki et al. researched this topic 1 year later in 2011 and found that the incidence of $\mathrm{PCa}$ (HR 1.25) and the risk of dying from $\mathrm{PCa}$ (HR 1.28) increased for patients with a FFH of PCa compared to nFFH. Using nearly the same sample, the authors did not differentiate between different subtypes of FFH this time, and additionally, the lack of treatment and sociodemographic data make a valid comparison with our results hardly possible [11]. In contrast, an American study from 2014 found no association between an FFH and high-risk disease or biochemical recurrence in a collective of 471 men after radical prostatectomy. When interpreting these results, one should consider that the authors relied on insufficient sample sizes (patients with an FFH $n=19$ ) and short follow-up periods (4-5 years).

Due to aforementioned findings, the role of FFH on longterm outcomes remains unclear. Therefore, we stratified FFH into four subtypes to evaluate this potential prognostic factor in detail. Moreover, the reference group consisted of patients with nFFH.
In multiple Cox regression, important risk factors for BRFS were especially pathological factors such as pathological tumor stage, pathological node stage, surgical margin, and pathological Gleason score. Neither FFH nor mode of inheritance was associated with BRFS.

Interestingly, our results showed that the Kaplan-Meier estimated CSS was slightly higher in patients with a pFFH compared to the other subgroups. Moreover, FFH was an important prognostic factor in the multiple Cox regression, with pFFH showing a better CSS compared to nFFH (HR: 0.19 CI 0.05-0.71). Unfortunately, using collected data, we cannot explain why a pFFH was associated with a better CSS. Earlier acquaintance of PCa due to a father's PCa diagnosis and lethal outcome could lead to a healthier lifestyle or higher perceived risk and PCa worry, which are, indeed, associated with preventive health behaviors such as screening initiation [19].

We also investigated the role of mode of inheritance in PCa. Patients of the MTM group had better Kaplan-Meier estimated CSS as well as higher HR of CSS in the simple Cox regression. However, due to the fact that it was not

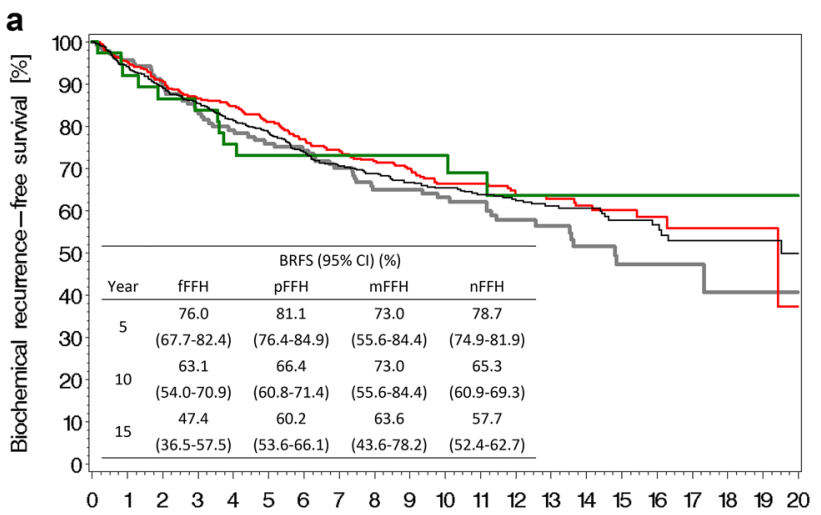

\section{b}

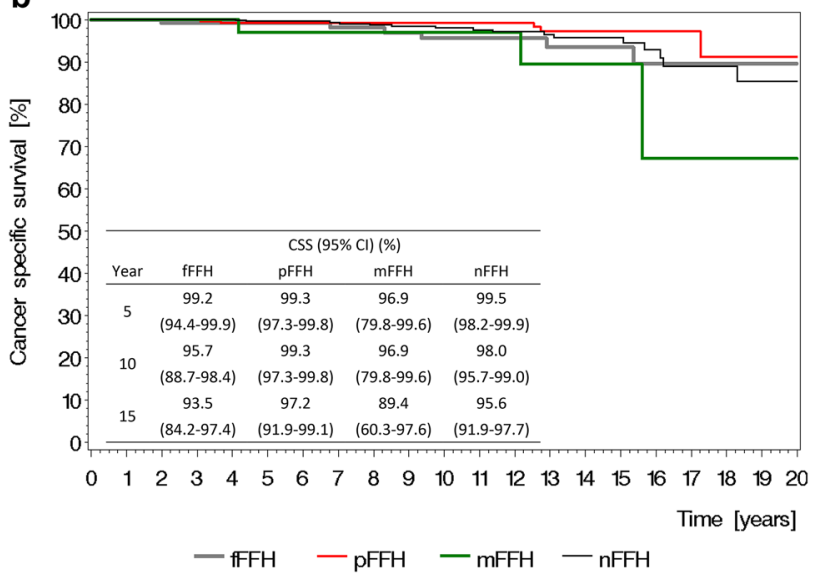

Fig. 1 a Overall biochemical recurrence-free survival (BRFS) and b Overall cancer-specific survival (CSS) stratified by fatal family history of prostate cancer with $95 \%$ confidence interval (CI) ( $F F H$ fatal family history, $f$ fraternal, $p$ paternal, $m$ multiple, $n$ none) 


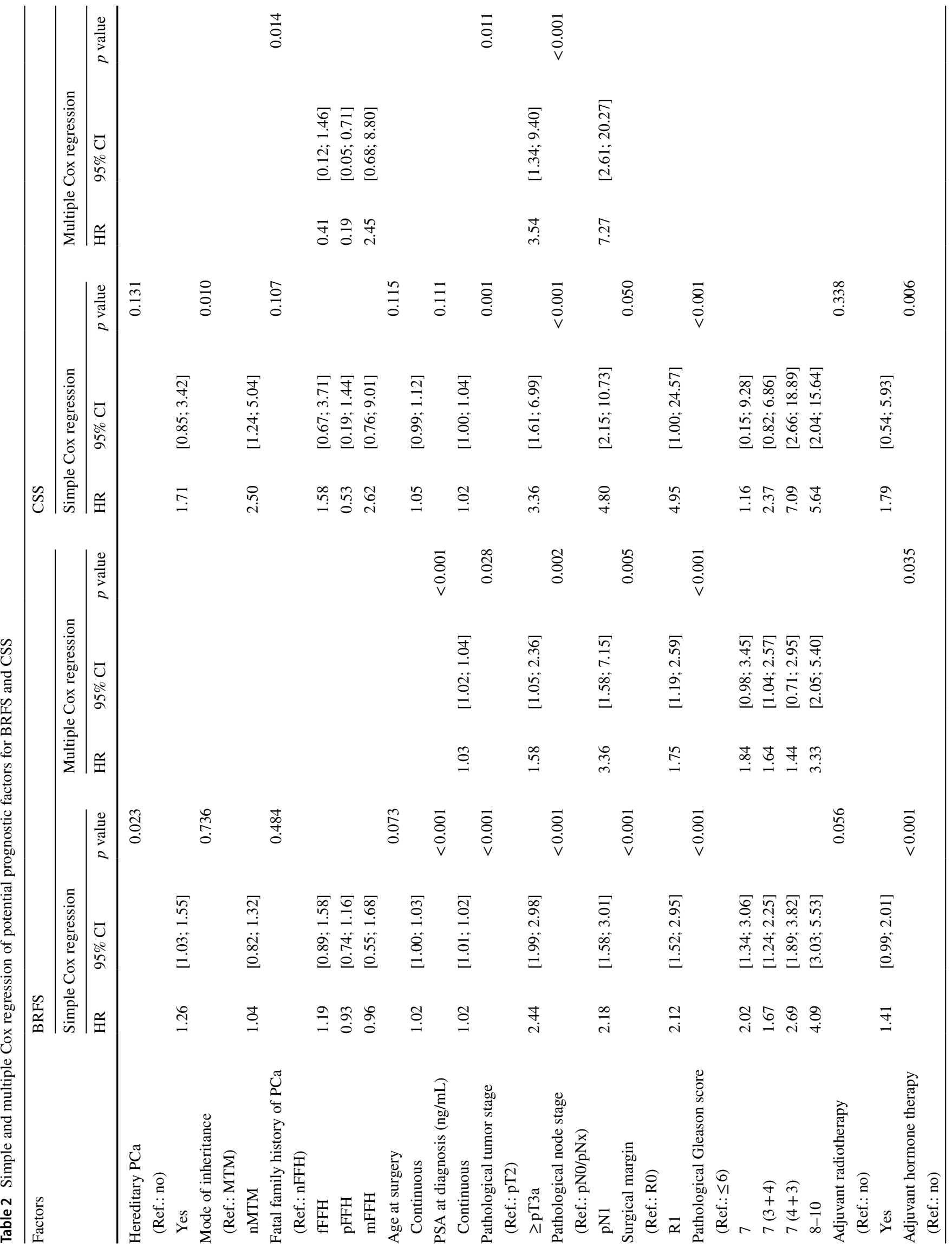



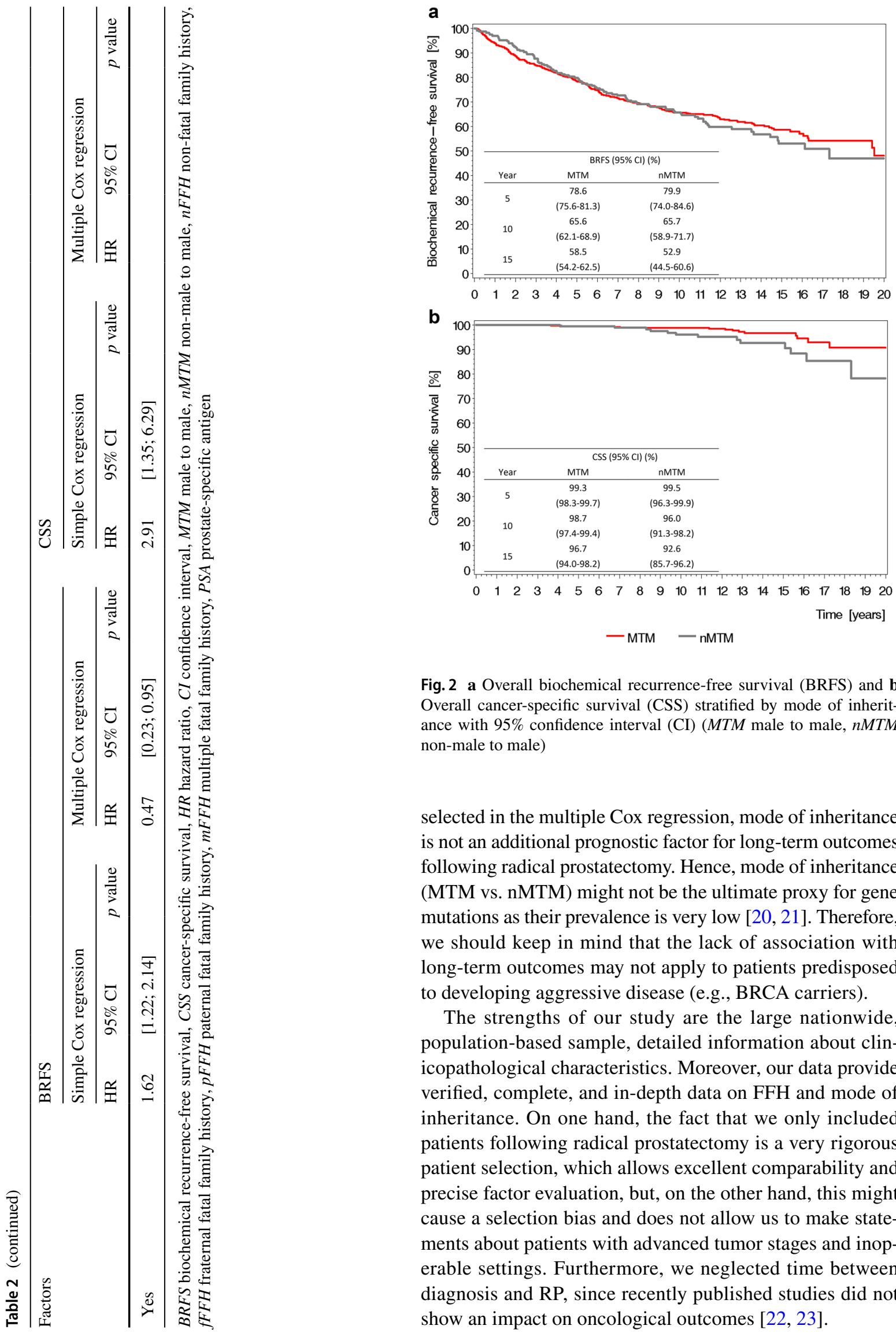

Fig. 2 a Overall biochemical recurrence-free survival (BRFS) and b Overall cancer-specific survival (CSS) stratified by mode of inheritance with $95 \%$ confidence interval (CI) (MTM male to male, $n M T M$ non-male to male)

selected in the multiple Cox regression, mode of inheritance is not an additional prognostic factor for long-term outcomes following radical prostatectomy. Hence, mode of inheritance (MTM vs. nMTM) might not be the ultimate proxy for gene mutations as their prevalence is very low [20,21]. Therefore, we should keep in mind that the lack of association with long-term outcomes may not apply to patients predisposed to developing aggressive disease (e.g., BRCA carriers).

The strengths of our study are the large nationwide, population-based sample, detailed information about clinicopathological characteristics. Moreover, our data provide verified, complete, and in-depth data on FFH and mode of inheritance. On one hand, the fact that we only included patients following radical prostatectomy is a very rigorous patient selection, which allows excellent comparability and precise factor evaluation, but, on the other hand, this might cause a selection bias and does not allow us to make statements about patients with advanced tumor stages and inoperable settings. Furthermore, we neglected time between diagnosis and RP, since recently published studies did not show an impact on oncological outcomes [22, 23]. 


\section{Conclusions}

Summarizing our result, we conclude that a positive FFH and mode of inheritance are not associated with worse longterm outcomes following radical prostatectomy. Conversely, a pFFH was rather an important prognostic factor for better CSS. Therefore, patients with deceased first-degree relatives due to PCa could be reassured that their own PCa diagnosis is not associated with a worse outcome if they are candidates for radical prostatectomy and undergo it.

Acknowledgements Open Access funding provided by Projekt DEAL.

Author contributions VHM: data management, and manuscript writing and editing, JGHS: data management and manuscript writing, MK: data management, data analysis, and manuscript editing, LAL: data collection and manuscript writing. SK: data collection and data management, JEG: protocol and project development, and manuscript editing, $\mathrm{KH}$ : protocol and project development, data management, and manuscript editing.

Funding There was no funding provided for this manuscript.

\section{Compliance with ethical standards}

Conflict of interest The authors declare that they have no conflict of interest.

Ethical approval The study was approved by the ethical review committee of the Technical University of Munich.

Research involving human participants and/or animals Anonymous data of human participants were involved in this study. Animals were not included in this study.

Informed consent Informed consent was obtained from all individual participants included in the study.

Open Access This article is licensed under a Creative Commons Attribution 4.0 International License, which permits use, sharing, adaptation, distribution and reproduction in any medium or format, as long as you give appropriate credit to the original author(s) and the source, provide a link to the Creative Commons licence, and indicate if changes were made. The images or other third party material in this article are included in the article's Creative Commons licence, unless indicated otherwise in a credit line to the material. If material is not included in the article's Creative Commons licence and your intended use is not permitted by statutory regulation or exceeds the permitted use, you will need to obtain permission directly from the copyright holder. To view a copy of this licence, visit http://creativecommons.org/licenses/by/4.0/.

\section{References}

1. Steinberg GD, Carter BS, Beaty TH, Childs B, Walsh PC (1990) Family history and the risk of prostate cancer. Prostate 17(4):337-347
2. Leitzmann MF, Rohrmann S (2012) Risk factors for the onset of prostatic cancer: age, location, and behavioral correlates. Clin Epidemiol 4:1-11. https://doi.org/10.2147/clep.S16747

3. Amini E, Palmer TC, Cai J, Lieskovsky G, Daneshmand S, Djaladat H (2018) Association between race and oncologic outcome following radical prostatectomy for clinically organ-confined prostate cancer: a long-term follow-up study. World J Urol 36(8):1233-1239. https://doi.org/10.1007/s00345-018-2266-y

4. Westerman ME, Gershman B, Karnes RJ, Thompson RH, Rangel L, Boorjian SA (2016) Impact of a family history of prostate cancer on clinicopathologic outcomes and survival following radical prostatectomy. World J Urol 34(8):1115-1122. https:// doi.org/10.1007/s00345-015-1738-6

5. Lee KL, Marotte JB, Ferrari MK, McNeal JE, Brooks JD, Presti $\mathrm{JC} \mathrm{Jr}$ (2005) Positive family history of prostate cancer not associated with worse outcomes after radical prostatectomy. Urology 65(2):311-315. https://doi.org/10.1016/j.urology.2004.09.005

6. Kotsis SV, Spencer SL, Peyser PA, Montie JE, Cooney KA (2002) Early onset prostate cancer: predictors of clinical grade. J Urol 167(4):1659-1663

7. Heck MM, Kron M, Gschwend JE, Herkommer K (2012) Effect of family history on outcome in German patients treated with radical prostatectomy for clinically localised prostate cancer. Eur J Cancer 48(9):1312-1317. https://doi.org/10.1016/j.ejca.2011.10.002

8. Brath JM, Grill S, Ankerst DP, Thompson IM Jr, Gschwend JE, Herkommer K (2016) No detrimental effect of a positive family history on long-term outcomes following radical prostatectomy. J Urol 195(2):343-348. https://doi.org/10.1016/j.juro.2015.07.097

9. Siddiqui SA, Sengupta S, Slezak JM, Bergstralh EJ, Zincke H, Blute ML (2006) Impact of familial and hereditary prostate cancer on cancer specific survival after radical retropubic prostatectomy. J Urol 176(3):1118-1121. https://doi.org/10.1016/j. juro.2006.04.077

10. Brandt A, Bermejo JL, Sundquist J, Hemminki K (2010) Agespecific risk of incident prostate cancer and risk of death from prostate cancer defined by the number of affected family members. Eur Urol 58(2):275-280. https://doi.org/10.1016/j.eurur o.2010.02.002

11. Hemminki K, Sundquist J, Brandt A (2011) Familial mortality and familial incidence in cancer. J Clin Oncol 29(6):712-718. https:// doi.org/10.1200/jco.2010.30.5664

12. Raheem OA, Cohen SA, Parsons JK, Palazzi KL, Kane CJ (2015) A family history of lethal prostate cancer and risk of aggressive prostate cancer in patients undergoing radical prostatectomy. Sci Rep 5:10544. https://doi.org/10.1038/srep10544

13. Castro E, Eeles R (2012) The role of BRCA1 and BRCA2 in prostate cancer. Asian J Androl 14(3):409-414. https://doi. org/10.1038/aja.2011.150

14. Xu J, Lange EM, Lu L, Zheng SL, Wang Z, Thibodeau SN, Cannon-Albright LA, Teerlink CC, Camp NJ, Johnson AM, Zuhlke KA, Stanford JL, Ostrander EA, Wiley KE, Isaacs SD, Walsh PC, Maier C, Luedeke M, Vogel W, Schleutker J, Wahlfors T, Tammela T, Schaid D, McDonnell SK, DeRycke MS, CancelTassin G, Cussenot O, Wiklund F, Gronberg H, Eeles R, Easton D, Kote-Jarai Z, Whittemore AS, Hsieh CL, Giles GG, Hopper JL, Severi G, Catalona WJ, Mandal D, Ledet E, Foulkes WD, Hamel N, Mahle L, Moller P, Powell I, Bailey-Wilson JE, Carpten JD, Seminara D, Cooney KA, Isaacs WB (2013) HOXB13 is a susceptibility gene for prostate cancer: results from the International Consortium for Prostate Cancer Genetics (ICPCG). Hum Genet 132(1):5-14. https://doi.org/10.1007/s00439-012-1229-4

15. Nordstrom T, Aly M, Eklund M, Egevad L, Gronberg H (2014) A genetic score can identify men at high risk for prostate cancer among men with prostate-specific antigen of $1-3 \mathrm{ng} / \mathrm{ml}$. Eur Urol 65(6):1184-1190. https://doi.org/10.1016/j.eururo.2013.07.005 
16. Thalgott M, Kron M, Brath JM, Ankerst DP, Thompson IM, Gschwend JE, Herkommer K (2018) Men with family history of prostate cancer have a higher risk of disease recurrence after radical prostatectomy. World J Urol 36(2):177-185. https://doi. org/10.1007/s00345-017-2122-5

17. Carter BS, Bova GS, Beaty TH, Steinberg GD, Childs B, Isaacs WB, Walsh PC (1993) Hereditary prostate cancer: epidemiologic and clinical features. J Urol 150(3):797-802

18. Mandel P, Kriegmair MC, Kamphake JK, Chun FK, Graefen M, Huland H, Tilki D (2016) Tumor characteristics and oncologic outcome after radical prostatectomy in men 75 years old or older. J Urol 196(1):89-94. https://doi.org/10.1016/j.juro.2016.01.009

19. McDowell ME, Occhipinti S, Chambers SK (2013) The influence of family history on cognitive heuristics, risk perceptions, and prostate cancer screening behavior. Health Psychol 32(11):11581169. https://doi.org/10.1037/a0031622

20. Lynch HT, Kosoko-Lasaki O, Leslie SW, Rendell M, Shaw T, Snyder C, D'Amico AV, Buxbaum S, Isaacs WB, Loeb S, Moul JW, Powell I (2016) Screening for familial and hereditary prostate cancer. Int J Cancer 138(11):2579-2591. https://doi.org/10.1002/ ijc. 29949

21. Kote-Jarai Z, Mikropoulos C, Leongamornlert DA, Dadaev T, Tymrakiewicz M, Saunders EJ, Jones M, Jugurnauth-Little S,
Govindasami K, Guy M, Hamdy FC, Donovan JL, Neal DE, Lane JA, Dearnaley D, Wilkinson RA, Sawyer EJ, Morgan A, Antoniou AC, Eeles RA (2015) Prevalence of the HOXB13 G84E germline mutation in British men and correlation with prostate cancer risk, tumour characteristics and clinical outcomes. Ann Oncol 26(4):756-761. https://doi.org/10.1093/annonc/mdv004

22. Morini MA, Muller RL, de Castro Junior PCB, de Souza RJ, Faria EF (2018) Time between diagnosis and surgical treatment on pathological and clinical outcomes in prostate cancer: does it matter? World J Urol 36(8):1225-1231. https://doi.org/10.1007/ s00345-018-2251-5

23. Aas K, Fossa SD, Kvale R, Moller B, Myklebust TA, Vlatkovic L, Muller S, Berge V (2019) Is time from diagnosis to radical prostatectomy associated with oncological outcomes? World J Urol 37(8):1571-1580. https://doi.org/10.1007/s00345-018-2570-6

Publisher's Note Springer Nature remains neutral with regard to jurisdictional claims in published maps and institutional affiliations. 